\title{
Non-invasive Imaging Methods for Brown Adipose Tissue Detection and Function Evaluation
}

Yaqi Zhang ${ }^{1 \#}$, Xiaofei Hu${ }^{2 \#}$, Su Hu${ }^{3,4 \#}$, Alessandro Scotti ${ }^{5,6}$, Kejia Cai $^{5,6}$, Jian Wang ${ }^{2}$, Xin Zhou ${ }^{7}$, Ding Yang ${ }^{8}$, Matteo Figini ${ }^{4}$, Liang Pan ${ }^{4,9}$, Junjie Shangguan ${ }^{4}$ Jia Yang ${ }^{4}$ and Zhuoli Zhang ${ }^{4,10^{*}}$

${ }^{1}$ Department of Obstetrics and Gynecology, Feinberg School of Medicine, Northwestern University, Chicago, IL, USA

${ }^{2}$ Department of Radiology, Third Military Medical University Southwest Hospital, Chongqing, China

${ }^{3}$ Department of Radiology, The First Affiliated Hospital of Soochow University, Suzhou, Jiangsu, China

${ }^{4}$ Department of Radiology, Feinberg School of Medicine, Northwestern University, Chicago, IL, USA

${ }^{5}$ Department of Radiology, University of Illinois at Chicago, Chicago, IL, USA

${ }^{6}$ Department of Bioengineering, University of Illinois at Chicago, Chicago, IL, USA

${ }^{7}$ Department of Cardiology, Pingjin Hospital, Tianjin, China

${ }^{8}$ Department of Biomedical Engineering, University of Florida, Gainesville, FL, USA

${ }^{9}$ Department of Radiology, The Third Affiliated Hospital of Soochow University, Changzhou, Jiangsu, China

${ }^{10}$ Robert H. Lurie Comprehensive Cancer Center, Northwestern University, Chicago, IL, USA

\#The first three authors contributed equally to this work

"Corresponding author: Zhouli Zhang, Department of Radiology, Northwestern University, 737 N Michigan Ave, 16 th Floor, Chicago, IL - 60611, USA, Tel No: +1-3126955753; E-mail: zhuoli-zhang@northwestern.edu

Received date: December 17, 2018; Accepted date: December 26, 2018; Published date: January 7, 2019

Copyright: $@ 2018$ Zhang Y, et al. This is an open-access article distributed under the terms of the Creative Commons Attribution License, which permits unrestricted use, distribution, and reproduction in any medium, provided the original author and source are credited.

\begin{abstract}
Brown Adipose Tissue (BAT) has a major role in thermoregulation, producing heat by non-shivering thermogenesis. Primarily found in animals and human infants, the presence of significant brown adipose tissue was identified only recently, and its metabolic role in adults was reconsidered. BAT is believed to have an important role in many metabolic diseases, such as obesity and diabetes, and also to be associated with cancer cachexia. Therefore, it is currently a topic of great interest in the research community, and many groups are investigating the mechanisms underlying BAT metabolism in normal and pathological conditions. However, well established noninvasive methods for assessing BAT distribution and function are still lacking. The purpose of this review is to summarize the current state of the art of these methods, with a particular focus on PET, CT and MRI.
\end{abstract}

Keywords: Brown adipose tissue; Imaging; Magnetic resonance; Positron emission tomography; Thermogenesis

\section{Introduction}

Brown adipose tissue (BAT) has been identified in healthy human adults and, because of its role in energy expenditure and thermogenesis; it has been regarded as a potential therapeutic target for treatment of obesity and cancer cachexia.

Monitoring the dynamics of BAT is critical for evaluating the effect of such treatments, but there are still no well-established non-invasive methods for assessing BAT distribution and function. In the first part of this paper we will overview BAT biology, including its definition and physiological function, the molecular pathways of its metabolism and its importance in pathological research.

In the second part we will review the current methods for noninvasive assessment of BAT, focusing on positron emission tomography (PET), computed tomography (CT) and magnetic resonance imaging (MRI), discussing their advantages, limitations and potential developments.

\section{Biology of Brown Adipose Tissue}

\section{Definition of BAT and physiological function}

BAT is a type of adipose tissue with distinct structural and metabolic properties compared to white adipose tissue (WAT). In particular, BAT plays an important role in thermogenesis, for both basal and inducible energy expenditure, because it contains a high number of mitochondria that can produce heat by burning triglycerides and glucose [1-6]. Although primarily being found in infants and young children, the presence of physiologically significant BAT was identified in healthy adult humans only less than a decade ago [1,7-9]. In humans, the anatomical distribution of BAT was mainly in cervical, supraclavicular and axillary areas [1]. Two different brown adipocytes lineages have been identified within the body: the classical constitutive brown adipocytes in the cervical and supraclavicular depots; and the inducible beige adipocytes in the supraclavicular, abdominal areas and other sites [10,11].

The activation of BAT thermogenic properties is initiated by the sympathetic nervous system during cold exposure for maintaining body temperature [12]. The activation of $\beta 3$-adrenergic receptors ( $\beta 3$ $\mathrm{AR})$ has also been identified as a trigger of thermogenesis in BAT [13]. 


\section{Molecular pathways of BAT metabolism}

BAT's capacity for activating energy expenditure without increasing physical activity is mediated by the mitochondrial uncoupling protein 1 (UCP-1) [14]. UCP-1 short-circuits the electron transport chain by increasing the permeability of the inner mitochondrial membrane, reducing the proton gradient generated in oxidative phosphorylation and allowing mitochondrial membrane potential to be transduced to heat [15-17]. The two distinct types of brown fat within the human body have been found to be associated with different levels of UCP1 expression: The classical brown fat has high $U C P 1$ expression, while the beige fat that emerges in white fat has extremely low expression of $U C P 1$ originally [11]. Under sympathetic stimulation and the interaction of norepinephrine with $\beta 3$-ARs, beige fat is stimulated to up regulate $U C P 1$ expression, leading to WAT browning [18]. Some key factors regulating $U C P 1$ activation include the peroxisome proliferator-activated receptor $\gamma$ coactivator-1a (PGC-1 $\alpha$ ) and the PR domain-containing protein 16 (PRDM16). Specifically, recruitment of PGC-1a to PRDM1, a transcription regulator of BAT formation, leads to powerful activation of BAT-selective gene expression and suppression of WAT-specific gene expression $[19,20]$.

BAT is also regulated by blocking of TGF- $\beta /$ Smad 3 signaling, which contributes to white-to-brown fat transformation by regulating PGC-1a and PRDM16 target genes [21]. Recently, the nuclear respiratory factor $1(\mathrm{Nrf1})$ was found to mediate the proteasomal activity, which is required for BAT thermogenic function [22].

\section{Importance of BAT in pathological research}

Due to the critical role of BAT in body energy metabolism, changes in BAT mass and activity could have great impact on metabolic disorders, especially in obesity and type-II diabetes [23-25]. As the activity of BAT was found to be decreased in mice with diet-induced obesity [26], activating BAT could be an effective way to increase energy expenditure. Treatment of rats with a highly selective $\beta 3$-AR agonist, CL-316,243, has been reported to stimulate the multilocular brown adipocytes that reside in WAT, which could be a potential therapeutic strategy for obesity [27]. Recently, Berberine, a compound from Coptis chinensis, was found to activate BAT thermogenesis and WAT browning [28]. Miglitol, an alpha-glucosidase inhibitor, was also reported to have anti-obesity activity through stimulating brown adipose tissue and energy expenditure, independent of its function in preventing post-prandial hyperglycemia [29].

Besides its potential in obesity treatment, BAT also plays an important role in glucose metabolism. BAT was found to have a much higher sensitivity to insulin than WAT, as the glucose uptake in BAT could be enhanced up to 5-fold after insulin perfusion [30]. Meanwhile, it is reported that patients with detectable BAT have higher insulin sensitivity and lower incidence of diabetes [31,32]. In addition, the triglyceride content in BAT was an independent factor associated with reduced insulin sensitivity, indicating the importance of BAT in type II diabetes [33].

On the other hand, the metabolic properties of BAT are thought to pathologically promote energy hyper metabolism in patients with cancer-associated-cachexia (Figure 1) [34], a syndrome of significant weight loss refractory to nutritional supplementation. It is believed that BAT hyperactivity and WAT browning switch contribute to the high energy expenditure in patients with cancer cachexia, which is induced by IL- 6 and tumor-derived parathyroid-hormone-related protein (PTHrP) [35,36]. Therefore, blocking the hyperactivity of BAT is increasingly considered as an effective method for reversing cancer cachexia.

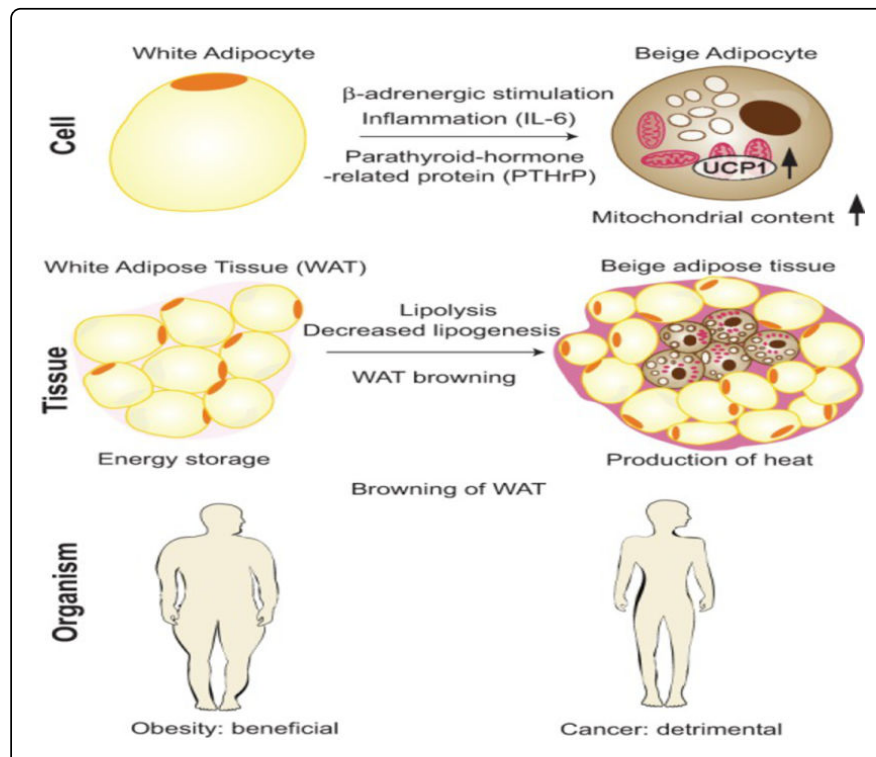

Figure 1: Mechanisms and consequences of WAT browning in cancer cachexia. At the "cell" level, beige adipocytes are induced in WAT by a combination of signaling pathways, including $\beta$ adrenergic stimulation, inflammation mediated by IL- 6 , and the presence of parathyroid-related peptide (PTHrP); as a result, UCP1 levels and mitochondrial content are increased. At the "tissue" level, CAC is associated with the appearance of islets of beige adipocytes in WAT, surrounded by white adipocytes of reduced size due to ongoing lipolysis. WAT browning and lipolysis result in decreased energy storage and increased production of heat. In the context of obesity, WAT browning is beneficial, while in cancer patients, it is detrimental. Reproduced from [34] under CC-BY-NC license.

\section{Non-invasive Measurement of BAT}

Despite the increased interest in BAT as a target for treatment of metabolic disorders and cachexia, there is still no well-established approach and standard protocol for the evaluation of BAT mass and function. Although histological stains can clearly discern BAT from WAT, biopsy sampling is limited and cannot reflect the volume and function of BAT in the whole body. Furthermore, biopsy is invasive and cannot be repeated multiple times in the same patient, as needed for clinical dynamic evaluations or longitudinal research studies. Recent reports using Cerenkov luminescence and Near Infrared Fluorescence showed potential for the in vivo study of BAT mass and function [37-40]. However, these studies have been performed only on mice, where the interscapular fat depot is superficial, whereas the human BAT is sparser and located more deeply, which makes it much harder to image with optical methods. A number of studies have shown that infrared thermography can detect BAT activation after cold stimulation and differentiate active and inactive BAT in animals and humans, but it still suffers from the same limitations as optical imaging [41-44].

Non-invasive imaging techniques for tracking and monitoring the BAT dynamic in patients are still much needed [45]. Currently, [18F] Fluorodeoxyglucose $\left({ }^{18} \mathrm{FDG}\right)$-PET imaging is the most commonly 
used method for measuring BAT function. Magnetic resonance imaging (MRI) and computed tomography (CT) techniques for BAT detection and characterization have been developed, and they have great potential for clinical diagnosis and management.

\section{PET}

PET is a highly sensitive and specific imaging tool for studying BAT physiology. Many radioactive tracers involved in energy metabolism have been applied for PET studies of BAT, including ${ }^{18} \mathrm{~F}-\mathrm{FDG},{ }^{15} \mathrm{O}$ tracers, ${ }^{11} \mathrm{C}$-Acetate, and ${ }^{18}$ F-Fluoro-thia-heptadecanoic acid $\left({ }^{18} \mathrm{FTHA}\right)[46] .{ }^{18} \mathrm{~F}-\mathrm{FDG}$ is the most widely used PET tracer in general, due to its relatively low cost, long half-life and physiological relevance to human metabolism, and it is also the most popular tracer for BAT studies. In combination with CT, ${ }^{8}$ F-FDG PET was the first method that brought to the rediscovery of BAT in adult humans [1,7]. Many studies have applied ${ }^{18} \mathrm{~F}-\mathrm{FDG}$ PET/CT for the quantitative characterization of BAT in different conditions, especially in cold exposure and insulin stimulation [47]. Furthermore, combining ${ }^{18} \mathrm{~F}$ FDG PET/CT and ${ }^{123 / 125}$ I- $\beta$-methyl-p-iodophenyl-pentadecanoic acid ( ${ }^{123 / 125}$ I-BMIPP) SPECT/CT, the depots of BAT tissue in rodents were identified, allowing the visualization of an adipose tissue atlas including a large number of additional areas of novel BAT pads. These animal studies suggest that additional regions may also exist in humans (Figure 2) [48].
A

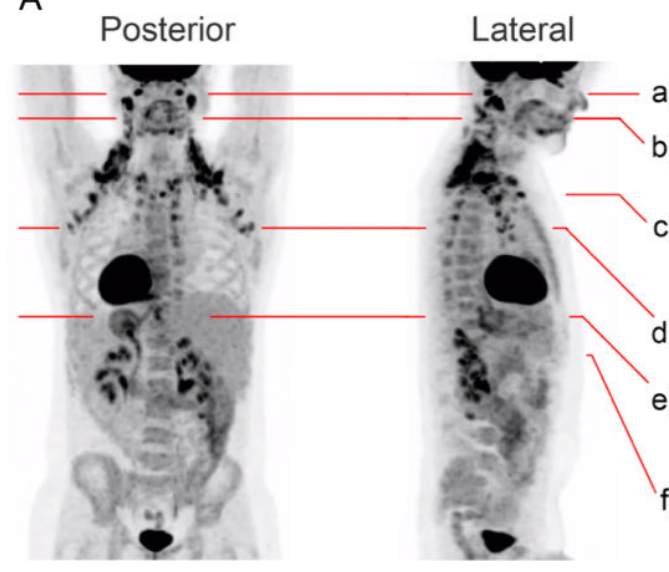

B

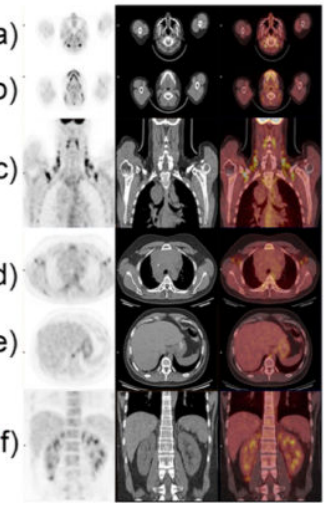

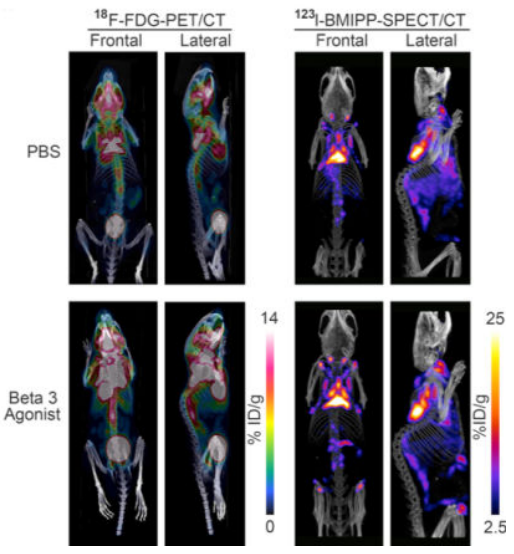

Figure 2: A: Regions of High-Level glucose Uptake in Humans as Assessed by ${ }^{18} \mathrm{~F}-\mathrm{FDG}-\mathrm{PET} / \mathrm{CT}$. Frontal and lateral maximal PET intensity projection images in an adult male subject imaged at room temperature show distribution of glucose uptake, mainly in the cervical, supraclavicular, axillary, intercostal, mediastinal, ventral spinal, and perirenal areas. Paravertebral tissue is also activated. Fat pads are also illustrated in multi-level transaxial or coronal PET/CT images (a-f). B: Anatomical Location of Metabolically Active Fat Pads in mice as Assessed by PET/CT and SPECT/CT. ${ }^{18} \mathrm{~F}-\mathrm{FDG}-\mathrm{PET} / \mathrm{CT}$ images show glucose uptake and distribution in the thermogenic tissues (left) and ${ }^{123}$ I-BMIPP-SPECT/CT show the patterns of fatty acid uptake in the metabolic active tissues (right) of an adult mouse kept at room temperature treated with 7 days of PBS (top) or $\beta 3$ agonist (bottom). Reproduced with permission from [48].

Although ${ }^{18} \mathrm{FDG}$ PET/CT has become the most common used platform for BAT imaging in clinics, several limitations still exist. First, PET results show a certain degree variability across different procedures and environmental conditions, since they are influenced by the injected amount and activity of radioactive tracers, by temperature and by the normalization of standard uptake values to body weight.

Also, as a glucose analog, the bio distribution of ${ }^{18} \mathrm{FDG}$ could be substantially altered by insulin injections levels. Thus, in order to provide guidelines and directly compare results among laboratories for describing the epidemiology and biology of human BAT, a set of criteria named "BARCIST1.0" has been published and recommended to researchers [49].

Another limitation is that ${ }^{18} \mathrm{FDG}$ PET is not specific to BAT but to any tissue with high glucose uptake, and it can only detect active as opposed to resting state BAT. More fundamentally, the precise correlation between ${ }^{18} \mathrm{~F}$-FDG uptake and thermogenesis is still unknown. In fact, ${ }^{18} \mathrm{~F}$-FDG uptake can be fully maintained even when oxygen consumption and BAT thermogenesis are diminished, suggesting that increased BAT ${ }^{18}$ F-FDG uptake can occur independently of thermal function [50]. An interesting alternative is the use of tracers like ${ }^{18} \mathrm{FTHA}$ and ${ }^{11} \mathrm{C}$-acetate, which can target BAT more specifically since fatty acids are the primary fuel for thermogenesis, and thus overcome some of the limitations associated to the glucose metabolism. However, increased uptake of fatty acids in BAT following cold exposure has not been conclusively demonstrated and experiments show somewhat contrasting results [46,51-53].

Furthermore, the exposure to radiations and the high cost of radiological equipment limit the feasibility of PET/CT for longitudinal studies or for some categories of subjects, such as pregnant women or children [54].

\section{CT}

In regular CT imaging, tissues with different chemical compositions could have similar attenuations. In particular, areas with negative Hounsfield Units (HU) are interpreted as fat, with no further discrimination between different types of adipose tissue. However, retrospective studies have found a $\mathrm{HU}$ increase during BAT activation, correlated with the uptake measured by PET $[55,56]$. Dual energy CT also has the potential of BAT measurement, as it is able to better 
differentiate the two fatty tissues by addition of an attenuation measurement at a secondary energy.

A recent study reported a method of xenon-enhanced CT for BAT imaging. As an excellent contrast agent, the inert lipophilic gas xenon preferentially accumulates in active BAT, therefore enhancing radio density of BAT in CT imaging and enabling the accurate quantification of the BAT mass [57].

\section{MRI}

Due to the limitations of PET/CT in identifying BAT, the application of MR imaging has been increasingly investigated. Versatility, higher spatial resolution, absence of ionizing radiation and lower cost make MRI the most promising technique for imaging BAT in clinics.
Different from the uni-locular adipocyte composition in WAT, BAT has multi-locular adipocytes with dense capillary and mitochondria, and thus its ratio of water to fat is compositionally distinct from that of WAT. By relying on protons signal, MRI is therefore able to image the distribution, structure and function of BAT.

The most well-established MRI method for BAT identification is water-fat separated MRI, which was originally introduced by Dixon for the purpose of fat suppression [58]. The protons of water and fat resonate at close but distinct frequencies, or chemical shifts. By acquiring two or more sets of images at different echo times, the contributions of water and fat to the signal can be deconvolved and a map of the fat-water proton ratio (fat fraction, FF) can be derived (Figure 3). Since BAT and WAT have different fat content, they can be differentiated based on FF values, which resulted to be above $90 \%$ for WAT and generally lower for BAT [59].

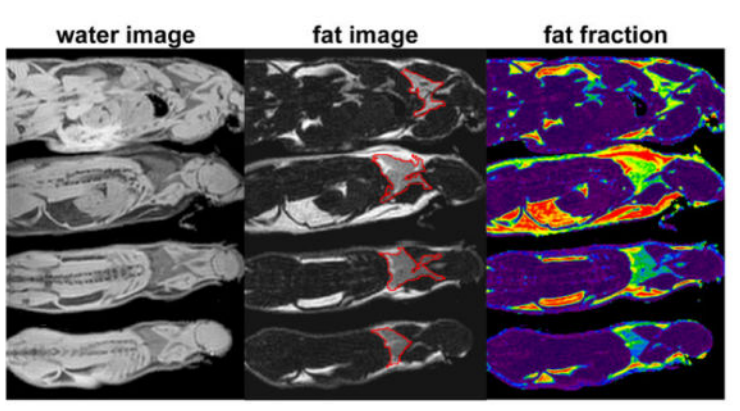

A
B
C

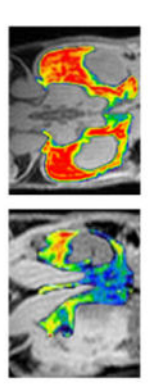

$\mathrm{D}$

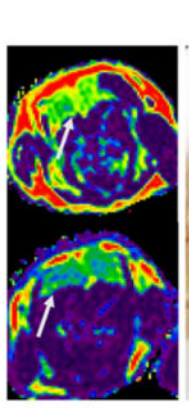

$\mathrm{E}$

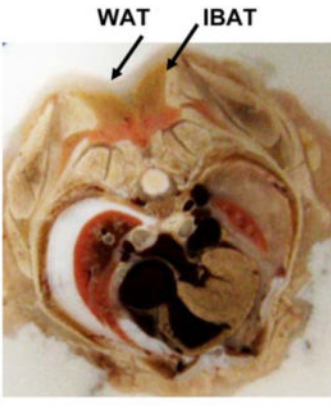

$\mathrm{F}$

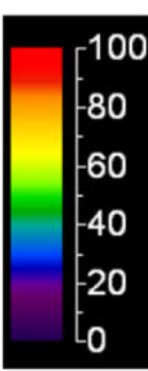

G

Figure 3: In situ identification of BAT in mice. A-C: Reconstructed water (A) and fat (B) images, and fat fraction map (C), with interscapular BAT depot (red contours in B). D: fat fraction map overlaid on water image, illustrating the peri-renal and inguinal adipose tissue depot in one adult (top) and one juvenile (bottom) mouse. Significant differences in the fat fraction maps are evident. Note particularly that the juvenile depot contains a mixture of WAT and BAT, whereas the adult depot is almost entirely WAT. E: Axial reformats highlighting the interscapular BAT (gray arrows) depot along the dorsal aspects of an adult (top) and a juvenile (bottom) mouse. F: Representative photo from axial cryosection of a separate animal (same gender, similar age and weight), Reproduced with permission from [59].

Several modifications to the original two-point Dixon technique have been implemented. The most relevant are the extension to asymmetric multi-echoes schemes [60,61]; the more detailed descriptions of the lipid spectral complexity, including up to 9 peaks $[62,63]$; the use of iterative algorithms for the decomposition of the signal [64,65]. Local changes due to field inhomogeneity or susceptibility variation can also be taken into account at the cost of a more refined processing algorithm. Despite the number of application in clinics and research [59,66-71], some critical aspects remain unsolved. As the technique is dependent on chemical shift, significant phase changes in the imaged volume can affect the reliability of the algorithms and lead to artifacts. In addition, the technique is mostly capable of imaging BAT distribution, whereas BAT function can be detected solely through FF variation over time $[63,72,73]$.

Blood Oxygen Level Dependent (BOLD) MRI is another technique that is being applied for BAT evaluation. The BOLD effect is based on the difference in susceptibility between oxygenated and deoxygenated hemoglobin, which causes changes in $\mathrm{T}^{*}$-weighted signal. As BAT usually has a greater capillary density than WAT, it is more sensitive to the changes in oxygen saturation level, blood flow and/or vascular volume. Thus, BAT activation, with greatly increased oxygen consumption, can be detected by BOLD MRI [74]. This has also been shown after stimulating BAT with cold challenge, showing a better resolution than 18F-FDG-PET/CT in distinguishing BAT from WAT (Figure 4) [75]; another study utilized the BOLD for identifying inactive and active BAT in the same adult combined with water-fat separation MRI and PET-CT [63].

The $\mathrm{T} 2^{*}$-weighted signal was also exploited for the detection of superparamagnetic iron oxides embedded in triglycerides-rich lipoproteins, which undergo uptake during BAT activation and therefore allow an almost real-time monitoring of the lipid metabolism [76].

Diffusion weighted MRI contrast has been shown to differentiate BAT from WAT based on the size of lipid droplets by utilizing extremely high diffusion weighting [77,78]. However, such high diffusion weighting is currently limited to NMR spectroscopic studies and poses challenges for clinical translation.

Recently, a study has proposed, Z-spectrum imaging as an alternative approach for FF quantification, inherently insensitive to field inhomogeneity and phase artifacts, showing promising results in mice and humans [79]. The technique is also currently under development for detection of BAT function, by measuring thermally- 
Page 5 of 7

induced chemical shifts and chemical exchange processes during activation.
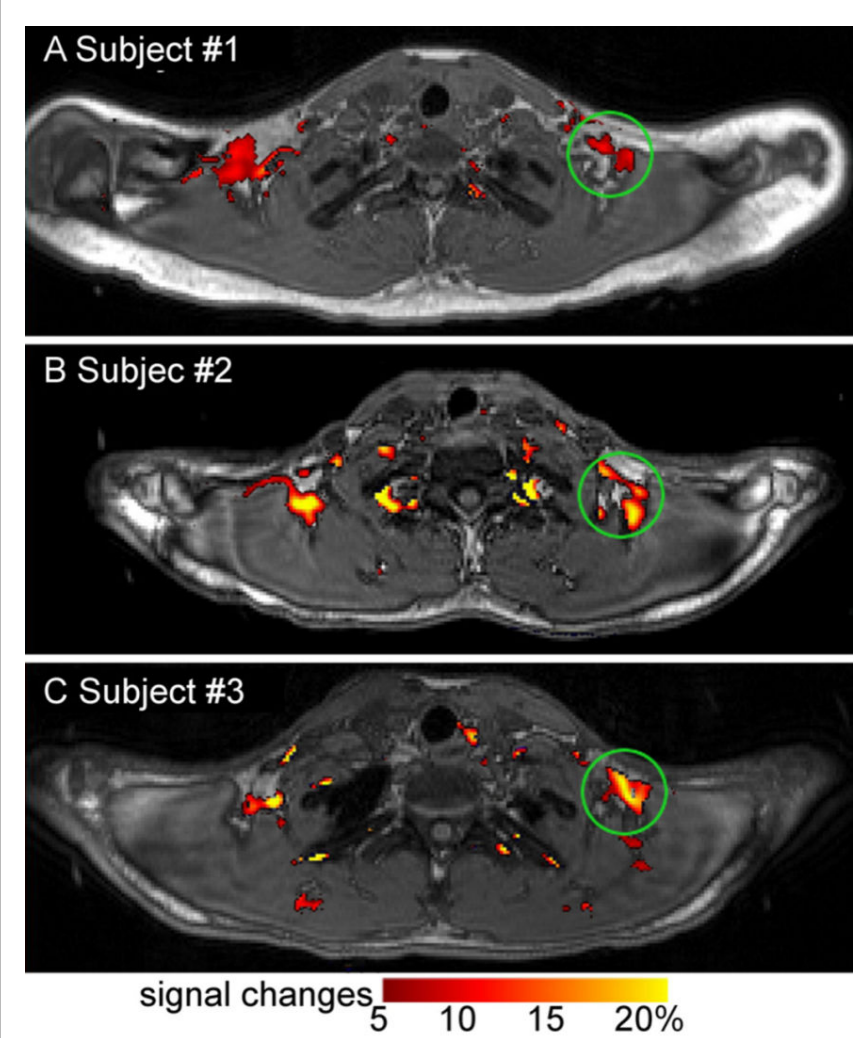

Figure 4: MRI detection of BAT activity upon cold challenge $\left(13^{\circ} \mathrm{C}-16^{\circ} \mathrm{C}\right)$. Degree of BOLD signal changes (red-yellow map) is superimposed on anatomical images (in grey scale). Upon cold stimulation, significant BOLD signal increases were found in the regions identified as having BAT for subjects \#1 - \#3 (such as areas indicated by green circles). Reproduced from [75] under CC-BYNC license

Other innovative and promising approaches continue to emerge, such as multiple quantum coherence MRI [80,81], hyperpolarized Xe gas imaging [82] and multispectral optoacoustic tomography in combination with MRI [83]. Although they have interesting contrast mechanisms, these techniques still face challenges in low signal to noise ratio and the requirement of exogenous contrast agents and/or special instruments that are not readily available in most of the clinical MRI scanners.

\section{Conclusion}

In recent years, the important role of BAT in maintaining body's metabolism and in development of diseases has been increasingly investigated. Therefore, the demand of methods for BAT characterization also increased.

Non-invasive imaging techniques have great potential to be applied in clinics. However, the potential of imaging methods that could be translated is also greatly influenced by the safety, cost and reproducibility, which determines the feasibility of wider application. Furthermore, as BAT could have changes in volume and activity in diseases, multimodal or multiparametric approaches capable of assessing both BAT morphology and function should be pursued.

\section{Acknowledgements}

This work was supported by the National Institutes of Health, National Cancer Institute grants R01CA196967 and R01CA209886.

\section{References}

1. Cypess AM, Lehman S, Williams G, Tal I, Rodman D, et al. (2009) Identification and importance of brown adipose tissue in adult humans. N Engl J Med 360: 1509-1517.

2. Anderson CM, Kazantzis M, Wang J, Venkatraman S, Goncalves RL, et al. (2015) Dependence of brown adipose tissue function on CD36-mediated coenzyme Q uptake. Cell Rep 10: 505-515.

3. Cannon B, Nedergaard J (2004) Brown adipose tissue: Function and physiological significance. Physiol Rev 84: 277-359.

4. Cypess AM, Haft CR, Laughlin MR, Hu HH (2014) Brown fat in humans: Consensus points and experimental guidelines. Cell Metab 20: 408-415.

5. Rosen ED, Spiegelman BM (2014) What we talk about when we talk about fat. Cell 156: 20-44.

6. Cannon B, Nedergaard J (2001) Respiratory and thermogenic capacities of cells and mitochondria from brown and white adipose tissue. Methods Mol Biol 155: 295-303.

7. Virtanen KA, Lidell ME, Orava J, Heglind M, Westergren R, et al. (2009) Functional brown adipose tissue in healthy adults. N Engl J Med 360: 1518-1525.

8. Nedergaard J, Bengtsson T, Cannon B (2007) Unexpected evidence for active brown adipose tissue in adult humans. Am J Physiol Endocrinol Metab 293: E444-452.

9. Lichtenbelt WD, Vanhommerig JW, Smulders NM, Drossaerts JM, Kemerink GJ, et al. (2009) Cold-activated brown adipose tissue in healthy men. N Engl J Med 360: 1500-1508.

10. Cypess AM, Weiner LS, Roberts-Toler C, Franquet Elia E, Kessler SH, et al. (2015) Activation of human brown adipose tissue by a beta3adrenergic receptor agonist. Cell Metab 21: 33-38.

11. Wu J, Bostrom P, Sparks LM, Ye L, Choi JH, et al. (2012) Beige adipocytes are a distinct type of thermogenic fat cell in mouse and human. Cell 150: 366-376.

12. Huttunen P, Hirvonen J, Kinnula V (1981) The occurrence of brown adipose tissue in outdoor workers. Eur J Appl Physiol Occup Physiol 46: 339-345.

13. Bachman ES, Dhillon H, Zhang CY, Cinti S, Bianco AC, et al. (2002) BetaAR signaling required for diet-induced thermogenesis and obesity resistance. Science 297: 843-845.

14. Nedergaard J, Golozoubova V, Matthias A, Asadi A, Jacobsson A, et al. (2001) UCP1: The only protein able to mediate adaptive non-shivering thermogenesis and metabolic inefficiency. Biochim Biophys Acta 1504: 82-106.

15. Porter C (2017) Quantification of UCP1 function in human brown adipose tissue. Adipocyte 6: 167-174.

16. Stanford KI, Middelbeek RJ, Townsend KL, An D, Nygaard EB, et al. (2013) Brown adipose tissue regulates glucose homeostasis and insulin sensitivity. J Clin Invest 123: 215-223.

17. Cannon B, Nedergaard J (2011) Non shivering thermogenesis and its adequate measurement in metabolic studies. J Exp Biol 214: 242-253.

18. Montanari T, Poscic N, Colitti M (2017) Factors involved in white-tobrown adipose tissue conversion and in thermogenesis: A review. Obes Rev 18: 495-513.

19. Uldry M, Yang W, St-Pierre J, Lin J, Seale P, et al. (2006) Complementary action of the PGC-1 coactivators in mitochondrial biogenesis and brown fat differentiation. Cell Metab 3: 333-341. 
20. Kajimura S, Seale P, Tomaru T, Erdjument-Bromage H, Cooper MP, et al. (2008) Regulation of the brown and white fat gene programs through a PRDM16/CtBP transcriptional complex. Genes Dev 22: 1397-1409.

21. Yadav H, Quijano C, Kamaraju AK, Gavrilova O, Malek R, et al. (2011) Protection from obesity and diabetes by blockade of TGF-beta/Smad3 signaling. Cell Metab 14: 67-79.

22. Bartelt A, Widenmaier SB, Schlein C, Johann K, Goncalves RLS, et al (2018) Brown adipose tissue thermogenic adaptation requires Nrf1mediated proteasomal activity. Nat Med 24: 292-303.

23. Holstila M, Pesola M, Saari T, Koskensalo K, Raiko J, et al. (2017) MR signal-fat-fraction analysis and $\mathrm{T} 2^{*}$ weighted imaging measure BAT reliably on humans without cold exposure. Metabolism 70: 23-30.

24. Nedergaard J, Cannon B (2010) The changed metabolic world with human brown adipose tissue: Therapeutic visions. Cell Metab 11: 268-272.

25. Cannon B, Nedergaard J (2009) Thermogenesis challenges the adipostat hypothesis for body-weight control. Proc Nutr Soc 68: 401-407.

26. Collins S, Daniel KW, Petro AE, Surwit RS (1997) Strain-specific response to beta 3-adrenergic receptor agonist treatment of diet-induced obesity in mice. Endocrinology 138: 405-413.

27. Himms-Hagen J, Melnyk A, Zingaretti MC, Ceresi E, Barbatelli G, et al. (2000) Multilocular fat cells in wat of CL-316243-treated rats derive directly from white adipocytes. Am J Physiol Cell Physiol 279: C670-681.

28. Zhang Z, Zhang H, Li B, Meng X, Wang J, et al. (2014) Berberine activates thermogenesis in white and brown adipose tissue. Nat Commun 5: 5493.

29. Sasaki T, Shimpuku M, Kitazumi T, Hiraga H, Nakagawa Y, et al. (2013) Miglitol prevents diet-induced obesity by stimulating brown adipose tissue and energy expenditure independent of preventing the digestion of carbohydrates. Endocr J 60: 1117-1129.

30. Orava J, Nuutila P, Lidell ME, Oikonen V, Noponen T, et al. (2011) Different metabolic responses of human brown adipose tissue to activation by cold and insulin. Cell Metab 14: 272-279.

31. Orava J, Nuutila P, Noponen T, Parkkola R, Viljanen T, et al. (2013) Blunted metabolic responses to cold and insulin stimulation in brown adipose tissue of obese humans. Obesity (Silver Spring) 21: 2279-2287.

32. Matsushita M, Yoneshiro T, Aita S, Kameya T, Sugie H, et al. (2014) Impact of brown adipose tissue on body fatness and glucose metabolism in healthy humans. Int J Obes (Lond) 38: 812-817.

33. Raiko J, Holstila M, Virtanen KA, Orava J, Saunavaara V, et al. (2015) Brown adipose tissue triglyceride content is associated with decreased insulin sensitivity, independently of age and obesity. Diabetes Obes Metab 17: 516-519.

34. Petruzzelli M, Wagner EF (2016) Mechanisms of metabolic dysfunction in cancer-associated cachexia. Genes Dev 30: 489-501.

35. Petruzzelli M, Schweiger M, Schreiber R, Campos-Olivas R, Tsoli M, et al. (2014) A switch from white to brown fat increases energy expenditure in cancer-associated cachexia. Cell Metab 20: 433-447.

36. Kir S, White JP, Kleiner S, Kazak L, Cohen P, et al. (2014) Tumourderived PTH-related protein triggers adipose tissue browning and cancer cachexia. Nature 513: 100-104

37. Yang J, Yang J, Ran C (2018) Spectral unmixing imaging for differentiating brown adipose tissue mass and its activation. Contrast Media Mol Imaging 2018: 6134186.

38. Zhang X, Kuo C, Moore A, Ran C (2013) In vivo optical imaging of interscapular brown adipose tissue with (18)F-FDG via Cerenkov luminescence imaging. PLoS One 8: e62007.

39. Azhdarinia A, Daquinag AC, Tseng C, Ghosh SC, Ghosh P, et al. (2013) A peptide probe for targeted brown adipose tissue imaging. Nat Commun 4: 2472.

40. Zhang X, Tian Y, Zhang H, Kavishwar A, Lynes M, et al. (2015) Curcumin analogues as selective fluorescence imaging probes for brown adipose tissue and monitoring browning. Sci Rep 5: 13116.

41. Crane JD, Mottillo EP, Farncombe TH, Morrison KM, Steinberg GR (2014) A standardized infrared imaging technique that specifically detects UCP1-mediated thermogenesis in vivo. Mol Metab 3: 490-494.
42. Ang QY, Goh HJ, Cao Y, Li Y, Chan SP, et al. (2017) A new method of infrared thermography for quantification of brown adipose tissue activation in healthy adults (TACTICAL): a randomized trial. J Physiol Sci 67: 395-406.

43. Gatidis S, Schmidt H, Pfannenberg CA, Nikolaou K, Schick F, et al. (2016) Is it possible to detect activated brown adipose tissue in humans using single-time-point infrared thermography under thermoneutral conditions? Impact of bmi and subcutaneous adipose tissue thickness PLoS One 11: e0151152.

44. Law J, Morris DE, Izzi-Engbeaya C, Salem V, Coello C, et al. (2018) Thermal Imaging Is a Noninvasive Alternative to PET/CT for Measurement of Brown Adipose Tissue Activity in Humans. J Nucl Med 59: 516-522.

45. Sampath SC, Sampath SC, Bredella MA, Cypess AM, Torriani M (2016) Imaging of brown adipose tissue: State of the Art. Radiology 280: 4-19.

46. Ouellet V, Labbe SM, Blondin DP, Phoenix S, Guerin B, et al. (2012) Brown adipose tissue oxidative metabolism contributes to energy expenditure during acute cold exposure in humans. J Clin Invest 122: 545-552.

47. Van der Lans AA, Wierts R, Vosselman MJ, Schrauwen P, Brans B, et al. (2014) Cold-activated brown adipose tissue in human adults: methodological issues. Am J Physiol Regul Integr Comp Physiol 307: R103-113.

48. Zhang F, Hao G, Shao M, Nham K, An Y, et al. (2018) An Adipose Tissue Atlas: An Image-Guided Identification of Human-like BAT and Beige Depots in Rodents. Cell Metab 27: 252-262.e253.

49. Chen KY, Cypess AM, Laughlin MR, Haft CR, Hu HH, et al. (2016) Brown Adipose Reporting Criteria In Imaging Studies (Barcist 1.0): Recommendations For Standardized Fdg-Pet/Ct Experiments In Humans. Cell Metab 24: 210-222.

50. Chen YI, Cypess AM, Sass CA, Brownell AL, Jokivarsi KT, et al. (2012) Anatomical and functional assessment of brown adipose tissue by magnetic resonance imaging. Obesity (Silver Spring) 20: 1519-1526.

51. Din MU, Raiko J, Saari T, Saunavaara V, Kudomi N, et al. (2017) Human brown fat radiodensity indicates underlying tissue composition and systemic metabolic health. J Clin Endocrinol Metab 102: 2258-2267.

52. Blondin DP, Labbe SM, Phoenix S, Guerin B, Turcotte EE, et al. (2015) Contributions of white and brown adipose tissues and skeletal muscles to acute cold-induced metabolic responses in healthy men. J Physiol 593: 701-714.

53. Blondin DP, Frisch F, Phoenix S, Guerin B, Turcotte EE, et al. (2017) Inhibition of intracellular triglyceride lipolysis suppresses cold-induced brown adipose tissue metabolism and increases shivering in humans. Cell Metab 25: 438-447.

54. Hu HH, Gilsanz V (2011) Developments in the imaging of brown adipose tissue and its associations with muscle, puberty, and health in children. Front Endocrinol (Lausanne) 2: 33.

55. Baba S, Jacene HA, Engles JM, Honda H, Wahl RL (2010) CT Hounsfield units of brown adipose tissue increase with activation: preclinical and clinical studies. J Nucl Med 51: 246-250.

56. Hu HH, Chung SA, Nayak KS, Jackson HA, Gilsanz V (2011) Differential computed tomographic attenuation of metabolically active and inactive adipose tissues: preliminary findings. J Comput Assist Tomogr 35: 65-71.

57. Branca RT, McCallister A, Yuan H, Aghajanian A, Faber JE, et al. (2018) Accurate quantification of brown adipose tissue mass by xenon-enhanced computed tomography. Proc Natl Acad Sci U S A 115: 174-179.

58. Dixon WT (1984) Simple proton spectroscopic imaging. Radiology 153: 189-194.

59. Hu HH, Smith DL, Jr., Nayak KS, Goran MI, Nagy TR (2010) Identification of brown adipose tissue in mice with fat-water IDEALMRI. J Magn Reson Imaging 31: 1195-1202.

60. Bhanu Prakash KN, Srour H, Velan SS, Chuang KH (2016) A method for the automatic segmentation of brown adipose tissue. Magma 29: 287-299. 
61. Lundstrom E, Strand R, Forslund A, Bergsten P, Weghuber D, et al. (2017) Automated segmentation of human cervical-supraclavicular adipose tissue in magnetic resonance images. Sci Rep 7: 3064

62. Hernando D, Kramer JH, Reeder SB (2013) Multipeak fat-corrected complex R2* relaxometry: theory, optimization, and clinical validation Magn Reson Med 70: 1319-1331.

63. Gifford A, Towse TF, Walker RC, Avison MJ, Welch EB (2016) Characterizing active and inactive brown adipose tissue in adult humans using PET-CT and MR imaging. Am J Physiol Endocrinol Metab 311 E95-e104.

64. Reeder SB, Pineda AR, Wen Z, Shimakawa A, Yu H, et al. (2005) Iterative decomposition of water and fat with echo asymmetry and least-squares estimation (IDEAL): Application with fast spin-echo imaging. Magn Reson Med 54: 636-644.

65. Deng J, Neff LM, Rubert NC, Zhang B, Shore RM, et al. (2018) MRI characterization of brown adipose tissue under thermal challenges in normal weight, overweight, and obese young men. J Magn Reson Imaging 47: 936-947.

66. Ma J (2008) Dixon techniques for water and fat imaging. J Magn Reson Imaging 28: 543-558.

67. Rasmussen JM, Entringer S, Nguyen A, van Erp TG, Burns J, et al. (2013) Brown adipose tissue quantification in human neonates using water-fat separated MRI. PLoS One 8: e77907.

68. MacCannell A, Sinclair K, Friesen-Waldner L, McKenzie CA, Staples JF (2017) Water-fat MRI in a hibernator reveals seasonal growth of white and brown adipose tissue without cold exposure. J Comp Physiol B 187: 759-767.

69. Reddy NL, Jones TA, Wayte SC, Adesanya O, Sankar S, et al. (2014) Identification of brown adipose tissue using MR imaging in a human adult with histological and immunohistochemical confirmation. J Clin Endocrinol Metab 99: E117-121.

70. Hu HH, Perkins TG, Chia JM, Gilsanz V (2013) Characterization of human brown adipose tissue by chemical-shift water-fat MRI. AJR Am J Roentgenol 200: 177-183.

71. Hu HH, Hines CDG, Smith DL, Reeder SB (2012) Variations in $\mathrm{T} 2^{*}$ and fat content of murine brown and white adipose tissues by chemical-shift MRI. Magnetic resonance imaging 30: 323-329.

72. Romu T, Vavruch C, Dahlqvist-Leinhard O, Tallberg J, Dahlstrom N, et al. (2016) A randomized trial of cold-exposure on energy expenditure and supraclavicular brown adipose tissue volume in humans. Metabolism 65 926-934

73. Van Rooijen BD, van der Lans AA, Brans B, Wildberger JE, Mottaghy FM, et al. (2013) Imaging cold-activated brown adipose tissue using dynamic $\mathrm{T} 2^{*}$-weighted magnetic resonance imaging and 2-deoxy-2-[18F]fluoroD-glucose positron emission tomography. Invest Radiol 48: 708-714.

74. Khanna A, Branca RT (2012) Detecting brown adipose tissue activity with BOLD MRI in mice. Magn Reson Med 68: 1285-1290.

75. Chen YC, Cypess AM, Chen YC, Palmer M, Kolodny G, et al. (2013) Measurement of human brown adipose tissue volume and activity using anatomic MR imaging and functional MR imaging. J Nucl Med 54: 1584-1587.

76. Bruns OT, Ittrich H, Peldschus K, Kaul MG, Tromsdorf UI, et al. (2009) Real-time magnetic resonance imaging and quantification of lipoprotein metabolism in vivo using nanocrystals. Nat Nanotechnol 4: 193-201.

77. Cao P, Fan SJ, Wang AM, Xie VB, Qiao Z, et al. (2015) Diffusion magnetic resonance monitors intramyocellular lipid droplet size in vivo. Magn Reson Med 73: 59-69.

78. Verma SK, Nagashima K, Yaligar J, Michael N, Lee SS, et al. (2017) Differentiating brown and white adipose tissues by high-resolution diffusion NMR spectroscopy. J Lipid Res 58: 289-298.

79. Scotti A, Tain RW, Li W, Gil V, Liew CW, et al. (2018) Mapping brown adipose tissue based on fat water fraction provided by Z-spectral imaging. J Magn Reson Imaging 6: 1527-1533

80. Branca RT, Warren WS (2011) In vivo brown adipose tissue detection and characterization using water-lipid intermolecular zero-quantum coherences. Magn Reson Med 65: 313-319.

81. Branca RT, Zhang L, Warren WS, Auerbach E, Khanna A, et al. (2013) In vivo noninvasive detection of Brown Adipose Tissue through intermolecular zero-quantum MRI. PLoS One 8: e74206.

82. Branca RT, He T, Zhang L, Floyd CS, Freeman M, et al. (2014) Detection of brown adipose tissue and thermogenic activity in mice by hyperpolarized xenon MRI. Proc Natl Acad Sci USA 111: 18001-18006.

83. Reber J, Willershauser M, Karlas A, Paul-Yuan K, Diot G, et al. (2018) Non-invasive Measurement of Brown Fat Metabolism Based on Optoacoustic Imaging of Hemoglobin Gradients. Cell Metab 27: 689-701. 